\title{
Violência Interpessoal e suas Repercussões na Saúde em um Hospital de Pronto-Socorro
}

\author{
Vanessa Russi Fiorini ${ }^{1}$ \\ Mariana Gonçalves Boeckel ${ }^{1}$
}

${ }^{1}$ Universidade Federal de Ciências da Saúde de Porto Alegre, Porto Alegre, Rio Grande do Sul, Brasil

\begin{abstract}
Resumo
A violência é um fenômeno multicausal, complexo, heterogêneo e uma questão de saúde pública. Quando ocorre na esfera interpessoal, deve ser compreendida como um evento biopsicossocial, causando graves repercussões. No Brasil, diante do atual cenário de violência, propôs-se a implementação do Sistema de Vigilância de Violências e Acidentes, objetivando o mapeamento e prevenção do fenômeno por ato notificatório. Com metodologia descritivo-transversal e coleta retrospectiva de dados, este estudo realizou levantamento de frequência e análises de associação. Constatou-se que a violência física foi a mais notificada e a mais relacionada às internações. Os atendimentos psicológicos atingiram um baixo índice de ocorrência, contrapondo a grande quantidade de encaminhamentos de saúde mental realizados. A arma de fogo apareceu como um dos principais meios de perpetração. Esses resultados, junto à constatação de uma morosidade existente no ato de notificar, evidenciam a gravidade do tema e a relevância de estudos nessa área.

Palavras-chave: violência, saúde, impactos na saúde, notificação
\end{abstract}

Interpersonal Violence and its Repercussions on Health at an Emergency Hospital

\begin{abstract}
Violence is a multicausal, complex, and heterogeneous phenomenon as well as a public health question. When it occurs in the interpersonal sphere, it must be understood as a biopsychosocial event with serious repercussions. In Brazil, given the concern due to the current violence scenario, it was proposed the implementation of the Violence and Accidents Surveillance System, with the objective of mapping and preventing the phenomenon, using the notification act. We conducted a frequency survey and association analyses using a descriptive-transversal methodology and retrospective data collection. It was verified that physical violence was the most reported, and the most associated to hospitalizations. Psychological services reached a low occurrence index, despite the high number of referrals to mental health support. Firearms appeared as one of the main means of violence perpetration. These results, along with the verification of a lengthy procedure for the notification act, evidence the severity of the theme and the relevance of studies in this area.

Keywords: violence; health; repercussions on health; notification
\end{abstract}

Violencia Interpersonal y sus Repercusiones en la Salud en un Hospital de Emergencia

\begin{abstract}
Resumen
La violencia es un fenómeno multicausal, complejo, heterogéneo y un problema para la salud pública. Cuando ocurre en el ámbito interpersonal, debe comprenderse como un evento biopsicosocial, causando graves repercusiones. En Brasil, ante la preocupación provocada por el escenario actual de violencia, se propuso la implementación del Sistema de Vigilancia de Violencias y Accidentes, con la finalidad de hacer un mapeo y prevenir el fenómeno, mediante un acto de notificación. Utilizando la metodología descriptiva transversal y la colección retrospectiva de datos, este estudio realizó una encuesta de frecuencia y análisis de asociación. Se constató que la violencia física fue la más denunciada, y la más relacionada con las internaciones hospitalarias. Los servicios de atención psicológica han alcanzado un bajo índice de ocurrencia, en contraste con el gran número de derivaciones remitidas a la red de salud mental. El arma de fuego apareció como uno de los principales medios de perpetración. Estos resultados, junto con la observación de un retraso en el acto de denuncia, evidencian la gravedad del tema y la necesidad fundamental de estudios en el área.

Palabras clave: violencia; salud; impactos en la salud; denuncia.
\end{abstract}

\section{Introdução}

A violência é um tema de relevância mundial, social e de saúde pública (World Health Organization [WHO], 2014) e pode ser definida como: uso realizado de maneira intencional de força física ou poder, podendo dar-se por meio de ameaça ou de forma concreta, contra si ou contra um grupo ou comunidade, tendo alta probabilidade de resultar ou resultando em lesão, dano psicológico, morte, prejuízo no desenvolvimento ou privação (WHO, 1996). A WHO (2014) reconhece a violência como um grave problema de saúde, além de constituir uma violação dos direitos humanos. Minayo e Souza (1998) apontam para a necessidade de a violência ser tratada como um fenômeno multicausal, complexo e que exige uma visão ampliada daquele que o estuda, 
pois exige abordagens epidemiológica, psicológica, social e biológica, devendo ser vista a partir de sua conjuntura social.

No Mapa da Violência (Waiselfisz, 2015), foi apresentada a evolução das vítimas fatais por armas de fogo entre os anos de 1980 e 2012, no Brasil, estando essa categoria dividida entre: acidente, suicídio, homicídio e indeterminado. Houve um aumento sistemático até o ano de 2003, com uma leve queda nos anos subsequentes, com os índices se mantendo constantes por volta das 39 mil mortes, para chegar ao pico de 42,4 mil em 2012. Entre jovens, de 15 a 29 anos, é importante salientar que esse número se encontra sempre maior do que entre a população em geral, tendo um crescimento de $272,6 \%$ no período mapeado.

No sentido de compreender melhor o fenômeno, é importante conhecer a população que pratica e a população que é vítima da violência. Sabe-se que os homens estão mais expostos a se envolverem em eventos violentos, pois a sociedade lhes impõe a necessidade de construir sua identidade a partir de comportamentos agressivos, viris e autoritários, aumentando o risco de tornarem-se agentes da violência; ao mesmo tempo, expõem-se a agressões e a outras formas de violência, tornando-se, também, alvos desta (Barreto, Teston, Latorre, Mathias, \& Marcon, 2016).

Almeida (2015) pontua que a violência interpessoal tem fortes impactos na vida das vítimas, causando um reordenamento social, sendo esses impactos não apenas estatísticos como também reverberados na organização de vida da comunidade. Para a WHO, a violência interpessoal pode ser mais bem definida como:

É considerada violência interpessoal aquela que ocorre entre membros da família, parceiros intimos, amigos, conbecidos e desconhecidos e inclui: maus-tratos à criança, violência juvenil (incluindo àquelas associadas a gangues), violência contra mulheres (por exemplo, violência conjugal e sexual), e violência contra o idoso. É diferente da violência autoprovocada e violência comunitária (WHO, 2014 p.2).

Quanto à natureza da violência interpessoal, esta se divide em dois subtipos, que referencia àqueles que a perpetram, sendo estes: intrafamiliar/parceiros íntimos e comunitária. Quando esta acontece no contexto intrafamiliar ou entre parceiros íntimos, ocorre, geralmente, no ambiente doméstico, apesar de não se limitar a esse lugar. Já quando a violência interpessoal é do subtipo comunitária, esta ocorre entre indivíduos não relacionados entre si e que podem conhecer-se ou não, acontecendo, normalmente fora da residência da vítima (WHO, 2002). Estima-se que no ano 2000 morreram 520.000 pessoas no mundo em decorrência da violência interpessoal, o que representa uma taxa de 8,8 pessoas a cada 100.000 . Ainda assim, diversas mortes se disfarçam e são compreendidas como acidentes, mortes naturais ou de causas desconhecidas, quando na verdade são fruto de violência interpessoal (WHO, 2002).

No Relatório Mundial sobre a Prevenção da Violência (WHO, 2014), os dados apontam para os países da América Latina como sendo aqueles com maior índice de homicídios do mundo, e a maior proporção $(75 \%)$ por meio de arma de fogo. No Brasil, uma das estratégias propostas, em decorrência do atual cenário de violência e da consequente preocupação do Estado com os seus impactos, pelo Ministério da Saúde, foi a implantação do Sistema de Vigilância de Violências e Acidentes (VIVA) no ano de 2006. Tal sistema, objetiva a avaliação e a caracterização da violência em diferentes lugares do país, a fim de criar estratégias de prevenção por meio desse mapeamento (Brasil, 2011). Venzi (2015) traz a importância do ato notificatório e o comprometimento dos profissionais de saúde com o atendimento às vítimas de violência, a partir do primeiro cuidado, que é fornecido por meio da notificação em saúde. Lima e Deslandes (2015) e Machado (2015) demonstraram que a violência interpessoal pode causar reverberações em diferentes eixos, como no cuidado em saúde e em uma população-alvo. Dahlberg e Krug (2006) caracterizam a violência por meio de sua epidemiologia e impactos. Além disso, alguns estudos, como o proposto por Moreira, Soares, Farias e de Souza Vieira (2015), retratam a situação atual das notificações relacionadas à violência sexual. A notificação dos atos violentos é o primeiro passo no sentido de dar visibilidade a esse tema e, a partir daí possibilitar a promoção de ações relacionadas ao combate à violência, sendo percebida a necessidade de uma atuação em rede da equipe de saúde (Venzi, 2015)

Apesar da grande quantidade de estudos que perpassam o tema da violência interpessoal, sua associação com os desfechos em saúde não tem aparecido recentemente na literatura. A partir da identificação da relevância do tema da violência e suas repercussões na vida de suas vítimas, o presente trabalho visa apresentar as características sociodemográficas da população vítima de violência atendida em um Hospital de Pronto-Socorro de uma capital do Brasil, assim como as características da violência interpessoal por elas sofrida. 


\section{Método}

Foi realizado um estudo descritivo-transversal, com coleta retrospectiva de dados realizada no contexto de um Hospital de Pronto-Socorro da cidade de Porto Alegre.

\section{Participantes}

Coletou-se dados de um total de 490 pacientes, vítimas de violência interpessoal, notificados por meio da ficha de notificação/investigação individual de violência doméstica, sexual e/ou outras violências interpessoais, já previamente preenchidas por profissionais da saúde de um Hospital de Pronto-Socorro na região metropolitana de Porto Alegre.

\section{Instrumentos para Coleta de Dados}

A Ficha de notificação/investigação individual de violência doméstica, sexual e/ou outras violências interpessoais (Brasil, 2006) foi criada a partir de uma série de políticas públicas implementadas pelo Ministério da Saúde que se ocupam do tema da violência, buscando a prevenção e promoção de saúde. Essa implementação é responsabilidade das Secretarias Estaduais de Saúde, em parceria com as Secretarias Municipais de Saúde, e tal registro deve alimentar o Sistema de Informação de Agravos de Notificação (SINAN), a partir dos dados obtidos (Brasil, 2011). A ficha é composta por variáveis e categorias que avaliam violências praticadas contra si, contra outra pessoa ou grupos populacionais (Brasil, 2006). O instrumento possui 69 itens para preenchimento, além das observações adicionais, que devem ser preenchidos pelo profissional que entrevistou e/ou atendeu a vítima de violência. Os itens incluem: dados gerais, notificação individual, dados de residência, dados da pessoa atendida, dados da ocorrência, violência sexual, dados do provável autor da agressão, encaminhamento, dados finais, informações complementares e observações e notificador. Para as notificações referentes à violência comunitária/extrafamiliar, o instrumento considera as seguintes populações: crianças, adolescentes, mulheres, população LGBT, pessoas com deficiência, indígenas e idosos. Já para a violência intrafamiliar, notificam-se homens e mulheres de todas as idades. Os dados apresentados neste trabalho referem-se às fichas preenchidas entre setembro de 2015 e novembro de 2016. A caracterização da amostra pode ser verificada nos resultados (Tabela 1).

O segundo instrumento utilizado foi o Prontuário Eletrônico, por meio do qual é possível realizar evoluções, solicitar consultorias, ter acesso aos exames e aos profissionais que atenderam o paciente, bem como a nota de alta e os motivos da internação. Buscaram-se os prontuários dos sujeitos notificados por meio da ficha a partir do registro do paciente no hospital. No prontuário dos pacientes, foram coletados os seguintes dados: ocorrência ou não de internação (e seu respectivo período), tipos de lesão, se houve ou não óbito, existência de encaminhamento (e o local e/ou locais para o(s) qual(is) se encaminhou) e informações sobre a existência - ou não - de atendimento psicológico no hospital.

\section{Procedimento para Coleta dos Dados}

Primeiramente, foram obtidos o consentimento e a autorização do local para acessar os dados no respectivo hospital. Após aprovação em Comitê de Ética, foi realizado contato com os profissionais responsáveis da instituição para agendamento dos turnos de coleta de dados. As informações obtidas foram tabuladas em planilhas do Excel e, posteriormente, exportadas para o SPSS.

\section{Procedimentos para Análise dos Dados}

Os dados obtidos foram analisados no SPSS 22.0, tendo sido realizado levantamento de frequência e análises de associação a partir do teste Qui-quadrado e do teste de exatidão de Fisher. Foi adotada como significância uma diferença estatística maior que $95 \%(p<$ $0,05)$.

\section{Procedimentos Éticos}

O projeto foi e aprovado pelo Comitê de Ética em Pesquisa (CEP) do Grupo Hospitalar (parecer 1.982.249) e pela Comissão de Pesquisa (COMPESQ) da Universidade a qual as autoras estão vinculadas (parecer 2.034.005). O estudo obedece às determinações da Resolução 466/12 do Conselho Nacional de Saúde e não houve riscos para os participantes por se tratar de uma pesquisa documental.

\section{Resultados e Discussão}

Primeiramente, apresenta-se a Tabela 1, a qual descreve os resultados referentes aos dados sociodemográficos.

O conhecimento dos dados sociodemográficos é de extrema importância para que seja possível entender a violência como fenômeno cultural (Minayo \& Souza, 1998). Esse conhecimento contempla um dos 
Tabela 1.

Dados Sociodemográficos

\begin{tabular}{|c|c|c|}
\hline Variáveis Sociodemográficas & $N(490)$ & $\%$ \\
\hline \multicolumn{3}{|l|}{ Sexo } \\
\hline Homens & 270 & 55,1 \\
\hline Mulheres & 220 & 44,9 \\
\hline \multicolumn{3}{|l|}{ Idade } \\
\hline Média & \multicolumn{2}{|c|}{$20,3(D P 18,4)$} \\
\hline \multicolumn{3}{|l|}{ Raça/Cor } \\
\hline Branca & 387 & 79 \\
\hline Preta & 79 & 16,1 \\
\hline Amarela & 1 & 0,2 \\
\hline Parda & 23 & 4,7 \\
\hline \multicolumn{3}{|l|}{ Escolaridade } \\
\hline Analfabeto & 130 & 27,0 \\
\hline Ensino Fundamental Completo & 296 & 61,4 \\
\hline Ensino Médio Completo & 54 & 11,2 \\
\hline Educação Superior Completa & 2 & 0,4 \\
\hline \multicolumn{3}{|l|}{ Situação Conjugal } \\
\hline Solteiro & 333 & 68 \\
\hline Casado/União consensual & 23 & 4,7 \\
\hline Viúvo & 2 & 0,4 \\
\hline Separado & 5 & 1 \\
\hline Não se aplica & 127 & 25,9 \\
\hline \multicolumn{3}{|l|}{ Orientação Sexual } \\
\hline Heterossexual & 130 & 26,5 \\
\hline Homossexual & 5 & 1 \\
\hline Não se aplica & 250 & 51 \\
\hline Ignorado & 105 & 21,4 \\
\hline \multicolumn{3}{|l|}{ Identidade de Gênero } \\
\hline Travesti & 3 & 0,6 \\
\hline Transexual mulher & 1 & 0,2 \\
\hline Não se aplica & 409 & 83,5 \\
\hline Ignorado & 77 & 15,7 \\
\hline Deficiência/Transtorno & 27 & 5,5 \\
\hline Atendimento Psicológico & 58 & 11,8 \\
\hline
\end{tabular}

objetivos de preenchimento da notificação de violência, sendo essa a possibilidade de mapear a população em maior risco e criar estratégias de prevenção em saúde (Brasil, 2010). Na amostra estudada, verificou-se a cor branca como mais prevalente dentre as vítimas $(79 \%)$, achado que contraria estudo de Souza, Mello
Jorge e Lima (2004), o qual demonstra que ser negro e ter baixa escolaridade podem ser fatores impactantes no aumento do risco de exposição de jovens à violência interpessoal. Os percentuais obtidos neste estudo sugerem a não existência de um perfil racial para que uma pessoa seja acometida pelo fenômeno da violência 
interpessoal. Contudo, ao mesmo tempo, é necessário que seja questionado sobre o percentual da população negra - 24,6\% ${ }^{1}$ em 2008, segundo IBGE, se forem somadas as categorias negra e preta - no Rio Grande do Sul, menos expressivo do que aquele encontrado em outras regiões do país. Assim, é possível ter a leitura, também, de que a disparidade encontrada entre as etnias, com relação ao acometimento da violência, refere-se às diferenças numéricas entre brancos e negros/ pretos no Rio Grande do Sul.

No que tange à diferença entre sexos, Barreto, Teston, Latorre, Mathias e Marcon (2016) apontam para a perpetuação de comportamentos violentos especialmente na população masculina, em todas as etapas da vida. Tal comportamento os colocaria como uma população de maior risco, quando comparada às mulheres. Esse dado se mostrou diferente nos casos coletados neste estudo, no qual houve uma quase paridade na distribuição de ocorrências por sexo - 55,1\% eram homens e $44,9 \%$ mulheres. As vítimas, em sua maioria, residiam em Porto Alegre $(77,6 \%)$ ou na região metropolitana $(20 \%)$. Obteve-se um baixo percentual de atendimento àquelas residentes no interior do estado ou litoral $(2,4 \%)$.

Quanto aos resultados referentes à escolaridade, demonstraram estar de acordo com o que foi apontado pelos autores (Souza, Mello, Jorge, \& Lima, 2004), pois a escolaridade da maior parte dos acometidos era baixa, sendo que $26,5 \%$ eram analfabetos e $60,4 \%$ possuíam ensino fundamental completo. Apenas dois participantes $(0,4 \%)$ possuíam ensino superior completo. A idade das vítimas apresentou grande amplitude, variando de zero (anos) a 88 anos, obtendo mediana de 16 anos, evidenciando maior incidência na população jovem.

A situação conjugal também apareceu como fator importante no acometimento da violência interpessoal, pois se averiguou que $68 \%$ das vítimas eram solteiras, o que demonstra a maior suscetibilidade dessa população ao fenômeno. Tal número se aproxima daquele encontrado por Patrício (2014), 72,97\% de solteiros, sendo este o estado civil preponderante dentre os acometidos por violência interpessoal entre os anos de 2001 e 2011, segundo os registros do Sistema de Informações de Mortalidade (SIM/Ministério da Saúde). Ainda com relação aos dados sociodemográficos, percebeu-se que, quando se fala em orientação sexual e identidade de gênero, existe uma falha no registro da notificação.

\footnotetext{
1 Se forem somadas as categorias morena, morena clara, parda,
} mestiça, mulata, negra e preta.

Psico-USF, Bragança Paulista, v. 26, n. 1, p. 129-140, jan./ mar. 2021
A orientação sexual foi notificada, majoritariamente, com assinalamentos nas opções "não se aplica" ou "ignorado", enquanto a identidade de gênero parece se referir somente àquelas transgêneras, não contemplando as cisgêneras, o que pode ser compreendido como um problema na elaboração do instrumento, evidenciando a necessidade de maior expressividade do tema na nossa sociedade.

O baixo percentual de atendimento psicológico recebido pelas vítimas no hospital $(11,8 \%)$ mostrou-se alarmante, especialmente pela necessidade apontada pela WHO (2014) no que diz respeito ao investimento no acolhimento e amparo às vítimas de violência nos serviços de saúde, incluindo o âmbito emocional. Tal atendimento é imprescindível para que se possa realizar a prevenção de novos casos de violência, bem como evitar a sua reincidência. Contudo, em estudo realizado por Barbosa, Dimenstein e Leite (2014), percebeu-se a dificuldade dos profissionais em realizarem esse acolhimento, vendo-se, por vezes, sem recursos na rede. Cabe discutir de que forma ocorrem esses encaminhamentos dentro da rede hospitalar e se tais demandas chegam à equipe de atendimento psicológico, sendo necessário repensar de que forma se estabelece o fluxo de atendimento nesse ambiente de constante emergência (física e psicológica), evitando a imposição de uma nova situação violenta devido à falta de acolhimento em saúde mental.

Dentre as variáveis importantes para se descrever o fenômeno da violência interpessoal, o tipo de violência infligida aparece como essencial para que se compreenda a natureza da agressão. $\mathrm{Na}$ Tabela 2, são apresentados os tipos de violência. O número de ocorrências ultrapassa os 490 casos estudados, pois, segundo as instruções da ficha, poderiam ser assinalados mais de um tipo de violência concomitantemente.

Destaca-se a violência física, a qual obteve um percentual de 70,2\%. Esse índice era esperado pelo fato de a violência ser, muitas vezes, compreendida como algo de cunho físico, que deixa marcas visíveis, contudo é necessário que haja uma preocupação, também, com as invisíveis. Atenta-se, nesse sentido, para os índices de ocorrência dos tipos negligência/abandono e psicológica/moral, com seus respectivos percentuais, 36,6\% e $21,1 \%$, que se mostraram expressivos. Foram registrados nove óbitos nos casos estudados, o que representa $1,8 \%$. Todos os casos de morte registrados estão relacionados à violência física. Apesar do percentual de óbito ter sido baixo, o ato notificatório se faz muito importante para que essas mortes sejam compreendidas 
como decorrentes da violência interpessoal, e não provocadas por acidentes ou provenientes de causas desconhecidas, tal como ocorre diversas vezes, como apontado pela WHO (2002).

Entende-se que os meios utilizados para executar o ato violento são relevantes para que se possa compreender as vicissitudes da população estudada, mais especificamente, como a violência se manifesta. Para tanto, na Tabela 3, apresentam-se os instrumentos/formas utilizados. Pode-se assinalar mais de um meio para cada notificação de violência, portanto, os números apresentados abaixo excedem, novamente, o $n$ de 490.

Destaca-se o uso da força corporal/espancamento $(48,5 \%)$, seguido pelo uso da arma de fogo $(27 \%)$. Waiselfisz (2015) descreve o incremento de $272,6 \%$ no uso de arma de fogo de 1980 a 2012, culminando em milhares de mortes anuais. De Melo, Sá e Sobrinho (2017) demonstraram que homicídios, especialmente os realizados com arma de fogo, ocupam o primeiro lugar dentre as mortes por causas externas. Tal fato precisa ser discutido quando se leva em conta que o porte de arma no Brasil não é sancionado para todos os civis, apesar de em âmbito político discutir a retomada do porte legal (Waiselfisz, 2015). Pode-se pensar no alto índice de uso de arma de fogo neste estudo como resultante de dado apontado por Carvalho e Espíndula (2016), estimando que, atualmente, circulam - sem controle do Estado cerca de 16 milhões de armas de fogo, estando 90\% em posse da sociedade civil e $48 \%$ delas sem registro. Outros resultados destacados foram o uso de ameaça, com $11,7 \%$ de ocorrência, objeto perfurocortante com $10,8 \%$ e objeto contundente com $8,3 \%$.

Tabela 2.

Tipos de Violência

\begin{tabular}{lcc}
\hline Tipos de Violência & $N$ & $\%$ \\
\hline Física & 342 & 70,2 \\
Negligência/Abandono & 178 & 36,6 \\
Psicológica/Moral & 103 & 21,1 \\
Outros & 51 & 10,5 \\
Financeira/Econômica & 18 & 3,7 \\
Intervenção legal & 12 & 2,5 \\
Tortura & 12 & 2,5 \\
Sexual & 4 & 0,8 \\
Trabalho infantil & 2 & 0,4 \\
Tráfico de seres humanos & 1 & 0,2 \\
\hline
\end{tabular}

Tabela 3.

Meios Utilizados na Violência Interpessoal

\begin{tabular}{lcc}
\hline Meios de Violência & $N$ & $\mathbf{\%}$ \\
\hline Força corporal/Espancamento & 167 & 37,5 \\
Arma de fogo & 120 & 27,0 \\
Outro & 113 & 25,4 \\
Ameaça & 52 & 11,7 \\
Objeto perfurocortante & 48 & 10,8 \\
Objeto contundente & 37 & 8,3 \\
Substância/Objeto quente & 18 & 3,7 \\
Enforcamento & 9 & 1,8 \\
Envenenamento/Intoxicação & 3 & 0,6 \\
\hline
\end{tabular}


Além disso, outro dado importante para a compreensão do fenômeno da violência é o conhecimento do provável autor da agressão. Para a WHO (2002), a violência interpessoal pode acontecer entre membros da família, parceiros íntimos, amigos, conhecidos e desconhecidos, ou seja, ocorre com a existência ou não de consanguinidade. Mais uma vez, apesar de o $n$ total ser de 490, o número total de prováveis autores excede o de casos notificados, pois era possível marcar mais de uma probabilidade autoral da violência infligida. A categoria "autor desconhecido" foi a mais assinalada dentre as opções de autoria, com $n$ de 114, obtendo 23,3\%. Destaca-se, como um achado surpreendente, a mãe como ocupando o segundo lugar dentre os autores ( $\operatorname{com} n$ de 103, representando 21\%). Amigos/Conhecidos totalizaram 62 registros (12,7\%), o pai obteve 53 notificações $(10,8 \%)$, enquanto o cônjuge totalizou 42 ocorrências $(8,6 \%)$. As demais categorias apareceram com menos de $4 \%$ de ocorrência cada, sendo elas, respectivamente: namorado (a) (3,5\%), filho(a) (3,5\%), cuidador $(2,9 \%)$, irmão(ã) $(2,4 \%)$, ex-cônjuge $(2,2 \%)$, policial/ agente da lei $(1,8 \%)$, padrasto $(1,6 \%)$, ex-namorado(a) $(1,4 \%)$, madrasta $(1,2 \%)$, pessoa com relação institucional $(0,6 \%)$ e patrão/chefe $(0,4 \%)$. Alguns achados, tais como a mãe ocupando o segundo lugar, quando se trata de perpetração da violência, ficam ainda mais claros quando se compreende a relação dos prováveis autores com os tipos de violência cometidos.

Assim, visando compreender de que maneira se dá a associação entre os tipos de violência e seus prováveis autores, apresenta-se a Tabela 4 , na qual se pode ver a relação entre os principais tipos de violência (vide Tabela 2) e os prováveis autores mais prevalentes.
Dentre os dados apresentados anteriormente, destaca-se a associação da violência física com autor desconhecido, amigo/conhecido e cônjuge. A violência psicológica/moral esteve associada ao cônjuge. Houve associação entre violência negligência/abandono e autoria de mãe ou pai. A associação encontrada entre a mãe e negligência/abandono é um achado importante, sendo que a mesma associação é encontrada quando se relaciona esse tipo de violência com a provável autoria do pai. Contudo, o número de casos de negligência/ abandono cometidos pela mãe $(n=97 ; 69 \%)$ constitui mais do que o dobro daquelas cometidas pelo pai $(n=$ $45 ; 32,4 \%)$. Nesse sentido, é importante que seja pensado o motivo de a mãe infringir mais atos violentos que o pai.

Assim, compreende-se que, mesmo com todas as mudanças de configuração familiares, ainda se observa a mãe assumindo de forma mais veemente a responsabilidade parental (Santos, 2015). Nesse sentido, poder-se-ia pensar que esta é a causa das mães cometerem mais atos negligentes, pois são elas que estão mais envolvidas com os filhos. Ademais, compreende-se que a violência contra filhos é um ato repetido de geração em geração e que, portanto, pode ser infringido tanto pela mãe, quanto pelo pai (Santos, 2015). Tal dado pode representar a dificuldade encontrada pela mãe em dar conta da função parental, seja por sentir-se sobrecarregada ou por não encontrar outras formas de resolução das dificuldades apresentadas, utilizando o meio da violência como uma estratégia intensamente ineficaz e inadequada para lidar com os estressores.

Pensando nos impactos que a violência causa em termos de saúde, esta pode resultar em lesão, agravo

Tabela 4.

Percentual de cada Possivel Autor por Tipo de Violência

\begin{tabular}{lccccccccc}
\hline & $\begin{array}{c}\text { Física } \\
(n=342)\end{array}$ & $\begin{array}{c}\text { Outra }^{1} \\
(n=138)\end{array}$ & $P^{*}$ & $\begin{array}{c}\text { Psic./ } \\
\text { Moral }^{2} \\
(n=103)\end{array}$ & $\begin{array}{c}\text { Outra }^{1} \\
(n=338)\end{array}$ & $P$ & $\begin{array}{c}\text { Neg./ } \\
\text { Aband. }^{3} \\
(n=178)\end{array}$ & $\begin{array}{c}\text { Outra }^{1} \\
(n=290)\end{array}$ & $P^{*}$ \\
\hline Desconhecido & 36,8 & 7,1 & $<0,001$ & 34,4 & 25,1 & $0,079 *$ & 11,9 & 38,6 & $<0,001$ \\
Mãe & 5,5 & 75,9 & $<0,001$ & 7,1 & 31,9 & $<0,001^{*}$ & 69,3 & 1,5 & $<0,001$ \\
Amigos/ & 21,5 & 0,9 & $<0,001$ & 17,7 & 15,3 & $0,580^{*}$ & 7,4 & 20,6 & 0,001 \\
Conhecidos & & & & & & & & & \\
Pai & 3,2 & 38,3 & $<0,001$ & 3,1 & 16,3 & $0,001 *$ & 32,4 & 1,9 & $<0,001$ \\
Cônjuge & 13,6 & 0,0 & $<0,001$ & 20,6 & 5,1 & $<0,001 * *$ & 2,0 & 14,1 & $<0,001$ \\
\hline
\end{tabular}

Nota. *Valor p para Qui-quadrado de Pearson; ** Valor $p$ para teste exato de Fisher. Os totais podem diferir devido a não-resposta.

Nota $2 .{ }^{1}$ Outra violência; ${ }^{2}$ Psicológica/Moral; ${ }^{3}$ Negligência/Abandono. 
psicológico, morte ou dano no desenvolvimento, gerando privação (WHO, 1996). Destarte o grande número de mortes diretamente relacionadas à violência, ainda mais indivíduos buscam serviços de saúde - especificamente os emergenciais - para tratar as repercussões advindas desse fenômeno (WHO, 2014).

Compreendendo que as lesões são parte importante desses impactos na saúde, apresenta-se como resultado da presente pesquisa a ocorrência de diferentes tipos de lesão notificado nos prontuários dos pacientes acometidos pela violência interpessoal. Em alguns casos, foram assinalados mais de um tipo de violência, enquanto em outros, não houve qualquer registro em prontuário acerca da lesão provocada, tal fato ocorreu especialmente quando os pacientes não foram internados.

Dentre os achados, destaca-se o percentual obtido pela categoria trauma $(33,1 \%)$, que englobou lesões, como: trauma crânio encefálico, fratura, escoriações e hematomas. Conforme a Organização Mundial da Saúde (WHO, 2002), esse tipo de lesão aparece em 90\% dos casos, relacionadas ao mecanismo de trauma, podendo ser originidas por causas intencionais (violência interpessoal) ou não intencionais, como quedas e acidentes de trânsito. Os adoecimentos dessa origem se destacam em nosso país, ocupando a terceira causa de óbitos. As lesões do tipo trauma foram seguidas pelas lesões de sistema digestivo $(8,4 / \%)$ e pelas lesões medulares $(6,7 \%)$, que ocupam, respectivamente, o segundo e terceiro lugar dentre as lesões. Atenta-se, ainda, para a queimadura, com 26 ocorrências, representando 5,3\% nos 490 casos estudados. Os demais tipos de lesão (infecção, alojamento de projétil, hemorragia e dor) obtiveram menos de 3\% de registro, cada.

Com relação aos encaminhamentos realizados às vítimas de violência pelos profissionais do hospital, notificados em prontuário, obteve-se uma gama diversa de locais para os quais os pacientes foram direcionados. É importante ressaltar que nem todos os pacientes obtiveram encaminhamentos, entretanto, alguns receberam mais de uma orientação.

O encaminhamento ao ambulatório do hospital foi o mais frequentemente realizado, com 26,7\% de ocorrência na população estudada. Destaca-se a porcentagem obtida pelos encaminhamentos ao Conselho Tutelar, de 19,4\%, às delegacias/plantões policiais $(6,8 \%)$ e ao posto de saúde $(6,7 \%)$, bem como a de encaminhamentos de saúde mental $(6,3 \%$ - 31 casos). Outros encaminhamentos realizados foram ao Centro de Atendimento à Mulher (3,5\%), ao CRAS $(1,8 \%)$ e a profissionais de saúde externos ao hospital $(1,4 \%)$.

Verificou-se o registro de alguns encaminhamentos menos notificados - com menos de $1 \%$ de ocorrência cada - respectivamente, instâncias jurídicas $(0,8 \%)$, Centro POP $(0,6 \%)$, DPVAT e Secretária de Saúde $(0,2 \%$ cada). Os achados referentes aos encaminhamentos de saúde mental mostram-se surpreendentes, se for considerada a baixa porcentagem de atendimento psicológico no ambiente hospitalar. Como indicam Mandelbaum, Schraiber e D'Oliveira (2016), algumas vezes se torna difícil para os profissionais da saúde compreenderem os impactos da violência na saúde psíquica em seu contexto cultural específico. Há uma clara associação entre a violência e o estabelecimento de impactos de sofrimento e dor que, por sua vez, reverberam na saúde pública, a qual necessita implementar estratégias de prevenção (Dahlberg \& Krug, 2006). Contudo, a prevenção não parece conseguir obter sua execução de maneira desejável. Desse modo, muitos encaminhamentos que acabam sendo realizados delegam para outras instituições cuidados que poderiam começar a ser estabelecidos dentro da instituição que acolhe inicialmente o paciente.

Ainda sobre esse resultado, precisa-se considerar que vários ingressos no hospital podem ter sido provenientes da violência interpessoal e passarem despercebidos. É necessário pensar de que modo se comportaria o sistema de saúde se esses casos fossem adequadamente notificados. Possivelmente esse dado seria ainda mais alarmante.

Os impactos causados pela violência, algumas vezes, exigem mais do que cuidados emergenciais, e algumas dessas vítimas imprescindem cuidados continuados por um determinado tempo, o que culmina na necessidade de internação. Dos 490 pacientes que sofreram algum tipo de violência interpessoal, 172 foram internados, o que representa $35,1 \%$ do total. Apesar do entendimento de que os casos de violência são subnotificados, um estudo realizado por Lozada, Mathias, Andrade e Aidar (2009) foi capaz de determinar que a violência interpessoal é a maior causa de atendimento e de internação nos adultos não idosos, tendo aumentado seu índice ao longo dos últimos anos.

A despeito do alto contingente de internação provocado por esse tipo de violência, os fatores que levam a esse aumento ainda não estão bem determinados. Broska Júnior, Folchini e Ruediger (2013) demonstraram que os motivos que levam ao aumento desses índices merecem uma investigação mais aprofundada, 
pois além do problema de saúde pública, a violência interpessoal acaba afetando uma parcela economicamente ativa da sociedade.

Por último, comparou-se a data de notificação com o dia em que ocorreu a violência (dado informado pelo paciente), demonstrando o tempo decorrido para o registro da notificação por meio da Ficha de Notificação de Violência Interpessoal/Autoprovocada (Brasil, 2006) após a ocorrência da violência. As notificações realizadas pelos profissionais de saúde ${ }^{2}$ no mesmo dia da ocorrência obtiveram um percentual de $17,1 \%$, enquanto a categoria de um a sete dias alcançou o maior índice de notificação (64,3\%). Como dados alarmantes, apareceram os percentuais obtidos pelas notificações preenchidas entre sete e trinta dias após a violência $(12,3 \%)$ e para àquelas realizadas entre trinta dias até um ano após (6,1\%). Por fim, com somente $0,2 \%$, apareceu a notificação realizada no período de um a dois anos após a infringência do ato violento - fatos que apontam para a existência de uma intensa morosidade no ato de notificar. Venzi (2015), Veloso, Magalhães, Dell'Aglio, Cabral e Gomes (2013) e Moreira et al. (2015) apontam para a importância de qualificar o ato notificatório, que muitas vezes acaba não sendo feito de maneira adequada, também pela alta rotatividade de profissionais na rede de saúde. Apesar das autoras apontarem o crescimento gradual no preenchimento das notificações, elas ressaltam a importância de se estabelecer parceriais entre a rede.

A partir dos dados coletados neste estudo, verificou-se, também, a importância de capacitar para o preenchimento, a fim de qualificar o modo como os profissionais respondem à ficha. A concretização dessas parceriais, bem como o treinamento de profissionais para o preenchimento desse instrumento são de extrema importância, pois, por meio desse preenchimento se pode caracterizar tipos e natureza das violências, suas vítimas e possíveis autores. A partir disso, é possível articular a rede para a criação de políticas públicas e estratégias de prevenção (Brasil, 2010).

\section{Considerações Finais}

Diante dos dados apresentados, compreende-se que a violência é, de fato, um fenômeno complexo e que gera muitos impactos, tanto na vida da população, quanto em termos de saúde pública. Dentre os

\footnotetext{
2 Referentes à data de ocorrência da violência informada pelo
} paciente.

Psico-USF, Bragança Paulista, v. 26, n. 1, p. 129-140, jan./mar. 2021 achados, destaca-se maior ocorrência do fenômeno na população de cor branca, diferente daqueles registros apresentados em outros estudos. Em concordância com o que aponta a literatura, verificou-se, neste artigo, que a violência física é ainda a mais infringida dentre os tipos de violência interpessoal, fato que pode estar relacionado a uma compreensão do ato violento como majoritariamente corporal, quando, na verdade, sabe-se dos danos psicológicos causados por sua perpetração. Nesse sentido, é imprescindível que se olhe para o número alarmantemente baixo de atendimentos psicológicos recebidos pelas vítimas no hospital. Entende-se que ainda há pouca capacitação para os profissionais da saúde para que possam compreender as repercussões causadas, em termos de saúde mental pelo fenômeno, o que acaba por gerar muitos encaminhamentos desse cunho, quando muitos desses casos poderiam ser acolhidos durante a internação dos sujeitos. Parece que, na maior parte dos casos, ainda existe uma concepção biomédica da saúde, e não um entendimento desta como biopsicossocial, modo a partir do qual se poderia entender as implicações da violência não apenas na saúde física, mas em outras esferas da vida do sujeito, tal como os graves danos emocionais.

Quanto aos autores da violência, identificaram-se os desconhecidos como aqueles que mais a praticam, o que causa a sensação de que a violência não te um rosto, fazendo, ao mesmo tempo, questionar quem são esses desconhecidos. Por outro lado, a mãe despontou como segunda principal autora dentre as violências interpessoais e primeira quando se trata do tipo negligência/ abandono. Esse dado é difícil de ser interpretado, pois, apesar do número bruto apontar para uma negligência materna maior do que a paterna, é necessário que se pense o porquê de ele aparecer dessa forma.

Destarte os números obtidos pela mãe, vale ressaltar que a violência tende a ser um fenômeno transgeracional, ou seja, pode ser infligido pela mãe, pelo pai, bem como ter sido efetuada por outros cuidadores de gerações anteriores. Ou seja, a violência geralmente tem uma longa história e precisa ser compreendida de forma complexa e contextual.

Os principais autores encontrados neste estudo se colocam como contraponto - a violência interpessoal está perto ou longe de casa? É perpetuada por aqueles que mais confiamos ou por pessoas que desconhecemos? Parece-nos possível dizer que, diante de suas inúmeras nuances, esse fenômeno é capaz de ser praticado tanto por pessoas as quais não conhecemos as feições, quanto por àquelas que nos são mais íntimas. 
Quando se pensa nos meios de perpetração do fenômeno, a arma de fogo aparece como o segundo mais recorrente de efetuar a violência, o que leva à seguinte pergunta: como isto é possível em um país em que o porte de arma, salvo algumas exceções, é proibido? O que isso significa em termos da banalização da violência nesse contexto? Precisa-se compreender os motivos pelos quais essas armas estão em circulação, levando a um círculo vicioso da violência: em uma sociedade armada há violência e há armas em decorrência de todo cenário violento. Em paralelo, pode-se pensar, diante dos dados de autoria da violência apresentados que essas armas, provavelmente, encontram-se ou nas ruas ou dentro das casas.

Pensando nos impactos da violência na saúde, este estudo foi capaz de relatar os de cunho físico, registrados em prontuário. Essas marcas aparentes, deixadas pelo fenômeno, apareceram, majoritariamente, em forma da lesão do tipo trauma, que foram também identificadas como as maiores responsáveis pela internação de pacientes. É importante pontuar que os danos à saúde, causados pela violência, não se restringem àqueles notificados no período em que $\mathrm{o}$ paciente permaneceu no hospital. Apesar dos poucos óbitos registrados neste trabalho, compreende-se que muitas vezes ela é capaz de deixar cicatrizes invisíveis por muito mais tempo. Esses danos não aparentes causados à vida do sujeito, por vezes, repercutem na saúde mental, o que indica a necessidade de se capacitar os profissionais de saúde, não apenas para melhor compreender e notificar o fenômeno violento, mas também para acolher e atender de maneira mais adequada e eficaz os pacientes por ela acometidos.

É necessário atentar para o fato de a violência ser considerada um fenômeno democrático, ou seja, não limita sua ocorrência a categorias de classe, raça, religião, etnia ou gênero, impactando a todos (Strey \& Cabeda, 2004). As multifaces da violência impedem que essa discussão se encerre neste artigo. As variâncias e repercussões desse fenômeno exigem que ainda muito mais estudos sejam realizados para que seja capaz de compreender como ele se comporta em diferentes contextos.

Por fim, considera-se importante pensar em melhorias para a ficha de notificação, especialmente no que tange as opções de resposta (como, por exemplo, ignorado e não se aplica), que confundem àqueles que preenchem, bem como à qualificação dos profissionais para que possam respondê-la de maneira mais adequada. Nesse sentido, uma limitação importante do presente estudo refere-se aos achados centrarem-se nas fichas de notificação, as quais nem sempre são corretamente e detalhadamente preenchidas. Ainda, sugere-se novos estudos que compreendam os impactos da violência e os números de notificações em diferentes contextos, como em Hospitais Gerais, visto que o presente estudo se limitou às notificações realizadas em um Hospital de Trauma, que possui um nicho específico de pacientes atendidos. Pensa-se, ademais, na importância da elaboração de intervenções de capacitação para a equipe - no sentido de qualificar, não somente o ato notificatório, como também a assistência aos pacientes no contexto do Sistema Único de Saúde e Política Pública de Assistência Social.

\section{Referências}

Almeida, J. F. (2015). Exposição à violência comunitária dos agentes da Estratégia Saúde da Família e repercussões sobre suas práticas de trabalho: um estudo qualitativo (Dissertação de mestrado não publicada). Universidade de São Paulo, São Paulo, Brasil.

Barbosa, L. B., Dimenstein, M., \& Leite, J. F. (2014). Mulheres, violência e atenção em saúde mental: questões para (re) pensar o acolhimento no cotidiano dos serviços. Avances en Psicología Latinoamericana, 32(2), 309-320. doi:10.12804/apl32.2.2014.09

Barreto, M.S., Teston, E. F., Latorre, M. R. D. O., Mathias, T. A. F., \& Marcon, S. S. (2016). Mortalidade por acidentes de trânsito e homicídios em Curitiba, Paraná, 1996-2011. Epidemiologia e Serviços de Saúde, 25(1), 95-104. doi:10.5123/S1679-49742016000100010

Brasil (2006). Ministério da Saúde. Sistema de informação de agravos de notificação: Normas e rotinas. Brasília, DF, Brasil. Recuperado de https://bit. ly/2MbJiW8

Brasil (2010). Ministério da Saúde. Linha de cuidado para a atenção integral à saúde de crianças, adolescentes e suas famílias em situação de violência orientações para gestores e profissionais de saúde. Brasília, DF, Brasil. Recuperado de https://bit. ly/2pWsEEm

Brasil (2011). Ministério da Saúde. Secretaria de Vigilância em Saúde. Viva: Instrutivo de notificação de violência doméstica, sexual e outras violências. Brasília, DF, Brasil. Recuperado de https://bit. ly/2NZtKee 
Broska Júnior, C. A., Folchini, A. B. D., \& Ruediger, R. R. D. (2013). Estudo comparativo entre o trauma em idosos e não idosos atendidos em um Hospital Universitário de Curitiba. Revista do Colégio Brasileiro de Cirurgiões, 40(4), 281-286. doi: 10.1590/ S0100-69912013000400005

Carvalho, L. A., \& Espíndula, D. H. P. (2016). Discussões em torno do referendo sobre o comércio de armas de fogo e munição na Folha de São Paulo. Opinião Pública, 22(2), 446-465. doi: 10.1590/1807-01912016222446.

Dahlberg, L. L., \& Krug, E. G. (2006). Violência: Um problema global de saúde pública. Ciênc. saúde coletiva, 11, 1163-1178. doi: 10.1590/ S1413-81232006000500007

De Melo, A., Sá, M., \& Sobrinho, J. (2017). Perfil epidemiológico da mortalidade por causas externas: Uma análise da literatura no Brasil. Revista De Saúde UniAGES, 1(1), 9-32. doi: 10.5205/1981-8963-v1 2i3a230886p716-728-2018

Lima, J. S., \& Deslandes, S. F. (2015). Olhar da gestão sobre a implantação da ficha de notificação da violência doméstica, sexual e/outras violências em uma metrópole do Brasil. Saúde e Sociedade, 24(2), 661-673. doi: 10.1590/S0104-12902015000200021

Lozada, E. M. K., Mathias, T. A. F., Andrade, S. M., \& Aidar, T. (2009). Informações sobre mortalidade por causas externas e eventos de intenção indeterminada, Paraná, Brasil, 1979 a 2005. Cadernos de Saúde Pública, 25(1), 223-228. doi: 10.1590/ S0102-311X2009000100024

Machado, C. B. (2015). A violência urbana e as repercussões nas ações de cuidado no território da saúde da família (Dissertação de mestrado não publicada). Universidade Federal Fluminense, Niterói, Rio de Janeiro, Brasil.

Mandelbaum, B., Schraiber, L. B., \& d'Oliveira, A. F. P. L. (2016). Violência e vida familiar: abordagens psicanalíticas e de gênero. Saúde e Sociedade, 25(2), 422-430. doi: 10.1590/S0104-12902016145768

Minayo, M. C. S., \& Souza, E. R. (1998). Violência e saúde como um campo interdisciplinar e de ação coletiva. História, Ciências, Saúde, 4(3), 513-531. doi: 10.1590/S0104-59701997000300006

Moreira, G. A. R., Soares, P. S., Farias, F. N. R., \& de Souza Vieira, L. J. E. (2015). Notificações de violência sexual contra a mulher no Brasil. Revista Brasileira em Promoção da Saúde, 28(3), 327-336. Recuperado de: https://bit.ly/2x460hZ

Patrício, A. P. (2014) O papel da violência interpessoal compreendida como a manifestação de uma endemia social: Uma análise geográfica sobre o fenômeno no Brasil e Rio Grande do Norte (Dissertação de mestrado não publicada). Universidade Federal do Rio Grande do Norte, Natal, Rio Grande do Norte, Brasil.

Santos, J. V. (2015). Maternidade e os fatores de violência na interação mãe filho (Dissertação de mestrado não publicada). Universidade Regional do Noroeste do Estado do Rio Grande do Sul, Ijú, Rio Grande do Sul, Brasil.

Souza, E. D., Mello Jorge, M. H., \& Lima, C. A. (2004). Impacto da violência na infância e adolescência brasileiras: Magnitude da morbimortalidade. Violência faz mal à saúde. Ministério da Saúde. Brasília. DF, Brasil. Recuperado de https://bit.ly/2NvgyRh

Strey, M. N., \& Cabeda, S. T. L. (2004). Corpos e subjetividades em exercício interdisciplinar (3). Porto Alegre: Edipucrs.

Veloso, M. M. X., Magalhães, C. M. C, Dell'Aglio, D. D., Cabral, I. R., \& Gomes, M. M. (2013). Notificação da violência como estratégia de vigilância em saúde: Perfil de uma metrópole do Brasil. Ciência \& Saúde Coletiva, 18(5), 1263-1272. Recuperado de https://bit.ly/2wTLHV6

Venzi, M. L. C. S. (2015). Violência e ficha de notificação: O que nós, profissionais de saúde, temos a ver com isso? Monografia de Especialização. CESMAD, Brasília, DF, Brasil.

Waiselfisz, J. J. (2015). Mapa da violência 2015: Mortes matadas por armas de fogo. São Paulo: Instituto Sangari. Recuperado de https://bit.ly/1CIONXS

World Health Organization (WHO) (1996). The world health report 1996: Fighting disease; Fostering development. Recuperado de https://bit. ly/2NXFIoF

World Health Organization (WHO) (2002). Informe mundial sobre la violencia y la salud: Resumen. Organización Panamericana de la Salud-Oficina Regional para las Américas de la Organización Mundial de la Salud. Washington, D.C, USA. Recuperado de https://bit.ly/WrmOvv 
World Health Organization (WHO) (2014). Global

Recebido em: 18/09/2018 status report on violence prevention 2014. RecuReformulado em: 22/03/2020 perado de https://bit.ly/12sUA5Y Aprovado em: 10/04/2020

Sobre as autoras:

Vanessa Russi Fiorini é Psicóloga pela Universidade Federal de Ciências da Saúde de Porto Alegre (2017) e mestra em Psicologia e Saúde pela UFCSPA (2020). Atua como psicóloga em um Centro de Referência de Assistência Social na Prefeitura Municipal de Guaíba. Coordenadora do Programa Criança Feliz e do Programa Primeira Infância Melhor no município de Guaíba/RS.

ORCID: https://orcid.org/0000-0002-9491-377X

E-mail: vanessarussifiorini@hotmail.com

Mariana Gonçalves Boeckel é Psicóloga pela Pontifícia Universidade Católica do Rio Grande do Sul (2002), mestrado em Psicologia pela Pontifícia Universidade Católica do Rio Grande do Sul (2004) e doutorado em Psicologia pela Pontifícia Universidade Católica do Rio Grande do Sul e Universitat de València (2013). É professora adjunto na Universidade Federal de Ciências da Saúde de Porto Alegre e do Programa de Pós Graduação Psicologia e Saúde na mesma Universidade. Atua, também, como terapeuta de família e de casais.

ORCID: https://orcid.org/0000-0002-2806-0238

E-mail: marianagb@ufcspa.edu.br

\section{Contato com as autoras:}

Universidade Federal de Ciências da Saúde de Porto Alegre

Rua Sarmento Leite, 245, sala 207, Centro Histórico

Porto Alegre-RS, Brasil

CEP: 90050-170

Telefone: $3303-8826$ 